\title{
JUSTIÇA RESTAURATIVA E ABOLICIONISMO PENAL: O PODER JUDICIÁRIO NO ENFRENTAMENTO À VIOLÊNCIA CONTRA MULHER
}

\author{
Rodrigo Cristiano Diehl* \\ Rosane Teresinha Carvalho Porto**
}

SUMÁRIO: Considerações Iniciais; 2 O Abolicionismo Penal (Des)Construção Necessária do Sistema Penal; 3 Entre Práticas Restaurativas e Retributivas: a Lei Maria da Penha, a Tipificação do Feminicídio e os Avanços e Desafios do Poder Judiciário; 4 Considerações Finais; Referências.

RESUMO: Com o presente estudo tem-se por objetivo analisar a Justiça Restaurativa e o abolicionismo penal dentro da lógica dos avanços e dos desafios do Poder Judiciário com as políticas públicas de enfrentamento a violência contra a mulher. Neste contexto, questiona-se: quais são os avanços e os desafios ao Poder Judiciário ao pensar em políticas públicas de enfrentamento a violência contra a mulher a partir da lógica da Justiça Restaurativa e do abolicionismo penal? Em termos conclusivos, encontrou-se que não basta aplicar a lei na busca pela punição, deve-se trabalhar com a prevenção e idealizando uma concepção valorativa e filosófica de justiça que auxilie as pessoas a caminharem rumo à erradicação da violência. Em matéria metodológica, utiliza-se como método de abordagem o materialismo dialético e como técnica de pesquisa a documental e a bibliográfica.

PALAVRAS-CHAVE: Abolicionismo penal; Justiça Restaurativa; Poder Judiciário; Políticas públicas; Violência contra a mulher.

\section{RESTORATION JUSTICE AND PENAL ABOLISHMENT: JURIDICAL AUTHORIT Y FACING VIOLENCE AGAINST FEMALES}

ABSTRACT: Restoration justice and penal abolishment are analyzed within the logic of progress and challenges that the Courts have to face within political policies in the wake of violence against women. Which are the challenges and the progress of the Courts within political policies in coping with violence against women as from the logic of Restoration Justice and penal abolishment? Results show that it is not sufficient to apply the law to mete punishment. Rather, one should prevent and idealize

\footnotetext{
Doutorando em Direito pela Universidade de Santa Cruz do Sul, com bolsa Prosuc/Capes, Brasil.

E-mail: rodrigocristianodiehl@live.com

${ }^{* *}$ Doutora em Direito pela Universidade de Santa Cruz do Sul. Docente de Direito da Infância e da Juventude e de Criminologia, na UNISC, Subcoordenadora do curso de direito UNISC, Campus de Sobradinho, Brasil.
} 
a valorative and philosophical concept of justice that would help people to eradicate violence. The paper employs dialectic materialism as a method, and documental and bibliographical research as a technique.

KEY WORDS: Penal abolishment; Restoration justice; Juridical power; Public policies; Violence against women.

\section{JUSTICIA RESTAURATIVA Y ABOLICIONISMO PENAL: EL PODER JUDICIARIO EN EL ENFRENTAMIENTO A LA VIOLENCIA EN CON- TRA LA MUJER}

RESUMEN: Con el presente estudio se tiene por objetivo analizar la Justicia Restaurativa y el abolicionismo penal dentro de la lógica de los avances y de los retos del Poder Judiciario con las políticas públicas de enfrentamiento a la violencia en contra a la mujer. En este contexto, se cuestiona: ¿cuáles son los avances y los retos al Poder Judiciario al pensar en políticas públicas de enfrentamiento a la violencia en contra a la mujer a partir de la lógica de la Justicia Restaurativa y del abolicionismo penal? En términos conclusivos, se encontró que no es suficiente aplicar la ley en la búsqueda por la punición, se debe trabajar con la prevención e idealizando una concepción valorativa y filosófica de justicia que ayude a las personas a caminar hacia a la erradicación de la violencia. En materia metodológica, se utiliza como método de abordaje el materialismo dialéctico y como técnica de investigación la documental y la bibliográfica.

PALABRAS CLAVE: Abolicionismo penal; Justicia Restaurativa; Poder Judiciario; Políticas públicas; Violencia en contra a la mujer.

\section{INTRODUÇÃO}

Com o advento da Lei Maria da Penha (Lei 11.340/2006) e com a lei que prevê o feminicídio como circunstância qualificadora do crime de homicídio (Lei 13.104/2015) a violência contra as mulheres passou a ter visibilidade na sociedade, diga-se de passagem, passou a ser intolerável, bem como a cultura patriarcal se fragilizou diante do poder feminino, que labuta historicamente para compartilhar espaços de poder com o homem.

Ainda é incipiente a força feminina, pois as próprias mulheres culturalmente ainda estão revestidas pelo patriarcado, o que sufoca e as confunde nas suas 
subjetividades. É interessante trazer para o estudo por parte da academia, o fato que o movimento feminista teve suas peculiaridades nos principais locais do mundo, cite-se: na França, nos Estados Unidos e na América do Sul. A distinção que se faz a respeito dessas peculiaridades assenta-se que tanto na França quanto nos Estados Unidos a luta fora pelos direitos políticos e, aqui na América do Sul, o movimento parece ter se reduzido ao debate ou enfrentamento da violência.

Nesse contexto, a presente pesquisa tem por intuito responder ao seguinte questionamento: quais são os avanços e os desafios ao Poder Judiciário ao pensar em políticas públicas de enfrentamento a violência contra a mulher a partir da lógica da Justiça Restaurativa e do abolicionismo penal? Por conta disso, tem-se por objetivo analisar a Justiça Restaurativa e o abolicionismo penal dentro da lógica dos avanços e dos desafios do Poder Judiciário com as políticas públicas de enfrentamento à violência contra a mulher.

$\mathrm{O}$ abolicionismo retira a resposta fácil buscada exclusivamente pela aplicação da legislação, faz com que os sujeitos pensem em alternativas de enfrentamento e combate à violência e fomentem a cultura da paz e a igualdade efetiva entre homens e mulheres. Contudo, para construir uma cultura de paz é preciso que os indivíduos internalizem os valores éticos voltados à coletividade e ao respeito pela diversidade na sociedade contemporânea.

Para a correta construção do trabalho utiliza-se como método de abordagem o materialismo dialético, uma vez que aborda e concebe os fenômenos naturais e sociais a partir do viés dialético, realizando a sua interpretação, seu modo de focalizá-los, na perspectiva materialista. Como última etapa da análise da metodologia tem-se as técnicas de pesquisa, das quais são utilizadas a documental e a bibliográfica com a finalidade de sistematizar o referencial teórico para encontrar possíveis respostas ao problema proposto, por meio dos objetivos geral e específicos, tendo por base tanto a identificação quanto a consulta à produção científica relevante acerca do tema. 


\section{O ABOLICIONISMO PENAL (DES)CONSTRUÇÃO NECESSÁRIA DO SISTEMA PENAL}

O abolicionismo penal é uma corrente política-criminal constituída por alguns pensadores, como Look Hulsman e Nils Christie ${ }^{03}$, contrários à existência e à operacionalidade do sistema penal, seletivo e excludente, bem como a monopolização do controle social pelo Estado. Além disso, o abolicionismo advém das políticas contraculturais dos anos 1960, propiciando o surgimento da teoria do etiquetamento e da nova criminologia ou criminologia crítica ${ }^{04}$.

O movimento criminológico abolicionista possui várias vertentes, desde a institucional, que apregoa o fim das prisões, ao reducionismo penal, que visa limitar a esfera de atuação jurídico-penal, passando pelo abolicionismo penal, que defende a própria extinção do sistema penal, até a sua forma mais radical, que refuta toda a forma de castigo ${ }^{05}$.

Os abolicionistas Hulsman ${ }^{06}$ e Nils Christie $^{07}$ se interessam por alternativa à Política Criminal, bem como consideram que o sistema penal intervém em muitos pontos que as pessoas envolvidas não vivenciam como delitos e acabam esquecendo da vítima no processo. Sustentam também que a intervenção do sistema penal agrava os conflitos e opera na lógica do castigo, porque impede de chegar qualquer resposta que não seja punitiva. Reconhecem que a prisão é reprodutora de criminalidade, sendo apenas uma alternativa à tortura e à pena de morte. Significa dizer, "Na prisão, os homens são despersonalizados e dessocializados”o8.

De igual maneira, entendem que a perspectiva penal é sempre dicotômica: branco-preto, criminoso-não-criminoso e culpado-inocente. Esse caráter binário constitui uma visão simples do homem e de seus atos, porque não permite contemplar todos os valores da coexistência humana. Em vez disso, seleciona somente aqueles que se relacionam com a lei ${ }^{09}$.

${ }^{03}$ CHRISTIE, N. A indústria do controle do crime. A caminho dos GULAGS em estilo ocidental. Rio de Janeiro: Forense, 1998.

${ }^{04}$ ACHUTTI, Daniel Silva. Justiça restaurativa e abolicionismo penal. São Paulo: Saraiva, 2014.

${ }^{05}$ ELBERT, Carlos Alberto. Novo manual de criminologia. Porto Alegre: Livraria do Advogado, 2009.

${ }^{06}$ HULSMAN, L.; CELIS, J. B. de. Penas perdidas. O sistema penal em questão. Rio de Janeiro: Luam, 1993.

${ }^{07}$ CHRISTIE, N. A indústria do controle do crime. A caminho dos GULAGS em estilo ocidental. Rio de Janeiro: Forense, 1998.

${ }^{08}$ HULSMAN, L.; CELIS, J. B. de. Penas perdidas. O sistema penal em questão. Rio de Janeiro: Luam, 1993. p. 63.

${ }^{09}$ ELBERT, Carlos Alberto. Novo manual de criminologia. Porto Alegre: Livraria do Advogado, 2009. 
Conforme Achutti ${ }^{10}$ :

O castigo, segundo os principais defensores da abolição do sistema penal, não é um meio adequado para reagir diante de um delito, e por melhor que possa vir a ser utilizado, ainda assim não surtirá os efeitos desejados, pois para além da finalidade mais latente (punir o criminoso), o sistema inteiro foi criado para perpetuar uma ordem social injusta, seletiva e estigmatizante, de forma que até mesmo sistemas que possuam um funcionamento tido como satisfatório não deixarão de ser violentos. Em outras palavras, a natureza do movimento abolicionista é heterogênea podendo se distinguir o abolicionismo penal radical, representado por Hulsman (que propôs o desaparecimento total do sistema), e o abolicionismo institucional, limitado a alcançar a supressão da instituição do cárcere com seus anexos, como os hospitais psiquiátricos forenses.

O conflito sobre o que se deve resolver desaparece quando é tratado, e os advogados são apenas tradutores do vocabulário cifrado que reduz a realidade. A busca por "uma solução" é um conceito puritano e etnocêntrico que não corresponde às experiências da vida, razão pela qual se diz que o amadurecimento se expressa na capacidade de suportar frustrações, ou seja, experiências sem solução ou sem satisfação para o indivíduo ${ }^{11}$.

Por outro lado, Hulsman ${ }^{12}$ concentra-se apenas na criminalidade tradicional, diz que o cidadão médio é um mito e que, quando as pessoas compreendem até que ponto o peso da maquinaria do castigo oprime nossas sociedades, não encontrará mais ninguém a defendê-la. Sustenta que a máquina de controle deve ocupar-se de $10 \%$ do total dos delinquentes, que sejam realmente perigosos ou tenham cometido atos muito danosos. Quanto ao resto do sistema, deve ser abolido, passado para a jurisdição civil aplicando-se seus processos, mecanismos, juízes e pessoal.

A prisão para Christie ${ }^{13}$ é um sofrimento não-criador, carente de sentido. As regras internas fazem prevalecer às relações de passividade, agressividade e dependência-dominação, que deixam lugar para a iniciativa nem o diálogo e alimentam o desprezo da pessoa. Na prisão se perde a personalidade e a sociabilidade e pensa-se

\footnotetext{
${ }^{10}$ ACHUTTI, Daniel Silva. Justiça restaurativa e abolicionismo penal. São Paulo: Saraiva, 2014. p. 91.

${ }^{11}$ ELBERT, Carlos Alberto. Novo manual de criminologia. Porto Alegre: Livraria do Advogado, 2009.

${ }^{12}$ HULSMAN, L.; CELIS, J. B. de. Penas perdidas. O sistema penal em questão. Rio de Janeiro: Luam, 1993.

${ }^{13}$ CHRISTIE, N. A indústria do controle do crime. A caminho dos GULAGS em estilo ocidental. Rio de Janeiro: Forense, 1998.
} 
que quem está na prisão teve o que merecia. Uma das críticas ao modelo abolicionista aponta para a excessiva e ingênua confiança na vítima; também que o seu futuro papel protagonista (reclamado especialmente por Christie) deve ir necessariamente acompanhado de uma diminuição do poder dos órgãos estatais para impor a solução, ou seja, de um modelo de Estado diferente ${ }^{14}$.

Seguindo a linha de pensamento, o abolicionismo vincula-se ao movimento contra a escravidão e de lá para cá, o pleito do movimento, daquele que se identifica como abolicionista, está em desconstruir a falácia do sistema penal e do sentido da pena, que não ressocializa, nem educa os sujeitos, ao contrário, aliena, exclui e escraviza, o que para o próprio sistema, enquanto braço do monopólio estatal é conveniente, pelo discurso estrategista de tirar de circulação, do meio, aqueles que são indesejáveis e se deseja apoderar, coisificar. Por isso, Foucault ${ }^{15}$ tangencia sobre o discurso. O discurso - como a psicanálise nos mostrou - não é simplesmente aquilo que manifesta (ou oculta) o desejo; é, também, aquilo que é o objeto de desejo; e visto que - isto a história não cessa de nos ensinar - o discurso não é simplesmente aquilo que traduz as lutas ou os sistemas de dominação, mas aquilo por que, pelo que se luta, o poder do qual nós queremos apoderar.

O discurso abolicionista é de reformar a culpa e a pena, pois é sabido que esta não regenera, nem atribui a responsabilidade individual e coletiva efetivamente. Nesse contexto, reconhece-se que o abolicionismo não é um novo paradigma e sim uma teoria, pois serve para sensibilizar e gerar maiores interrogações, sobre o que está posto no campo social, retroalimentado pela cultura jurídica punitiva e não declarada ${ }^{16}$.

Com efeito, Hulsman e Celis ${ }^{17}$ não veem sentido nas penas, até porque entendem que a administração de conflitos pelo Estado precisa ser repensada, abolida, diga-se de passagem, descentralizada, ou seja, de retirar do poder público a autonomia na regulação de conflitos, pois a estrutura das sanções apenas retroalimenta o poder simbólico do sistema penal. É necessário um sistema de gestão de conflitos mais autônomo, parecido com algumas comunidades tribais, se dando a regulação de conflitos no nível de intergrupos e de relações diretas entre indivíduos com a ajuda de instituições ou procedimentos próximos e que observem a experiência

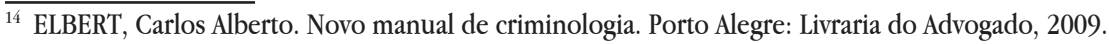

${ }^{15}$ FOUCAULT, Michel. A ordem do discurso. 3. ed. São Paulo: Loyola, 1996.

${ }^{16}$ SCHEERER, H.; STEINERT, C.; FOLTER, M. Abolicionismo penal. Buenos Aires: Ediar Sociedad Anónima, 1989.

${ }^{17}$ HULSMAN, L.; CELIS, J. B. de. Penas perdidas. O sistema penal em questão. Rio de Janeiro: Luam, 1993. 
direta das pessoas para se trabalhar com dimensão da ética do cuidado com o outro e a responsabilidade dos atos decididos e tomados pelo indivíduo.

O abolicionismo de Mathiesen é muito peculiar, pois não trata de abolir algo e sim de esclarecer, de convidar a pensar sobre o sistema de penas que está posto e aplicado dentro das sociedades. Em outras palavras, implica abolir com um sistema social repressivo, partindo da reflexão, em que é fundamental romper com a ordem estabelecida e ao mesmo tempo enfrentar o que está posto, para reconstruir algo. Sobre a fundamentação metodológica do abolicionismo tanto Foucault, como para Deleuze: "la liberación de la diferencia requiere un pensamiento sin contradicción, sin dialéctica, sin negación: un pensamiento de lo múltiple, de la multiplicidad nómade y dispersa que no está limitada o confinada por las restricciones de la similitud". Significa dizer, o abolicionismo está relacionado com o princípio da solidariedade, pela abordagem humanista em relação aos excluídos e ou marginalizados sociais $^{18}$.

Em meados do século XXI, a sociedade comporta-se como a do século XIII, em que no Brasil o sistema penal e o prisional foram articulados para funcionar pela lógica punitiva. Nesse cenário de retrocesso, com estratégias de aprisionamento melhor elaboradas, existem os crimes passionais e de ódio cometidos contra as mulheres pelos seus companheiros, pela violação dos seus direitos fundamentais.

A partir do século XVIII o ente estatal ganhou a titularidade da ação penal e o direito de punir quem infringisse os padrões comportamentais sociais adequados previstos em normas positivadas. Porém, embasado na coação e na repressão, o direito concorreu - e ainda concorre - para produzir um tipo de sociedade sustentada sobre relações de força e de poder.

Daí, consequência dessa forma de pensar e de agir culminou na estruturação de um modelo punitivo, que encontrou a sua forma de expressão na criação da mais concreta imagem de violência; eleita, justificada e sustentada pelas instituições sociais e políticas - dominadoras do poder - como o principal instrumento de resposta aos comportamentos desviantes, a saber: a prisão. Constrói-se aquilo que Foucault denomina de sociedade punitiva, um tipo de sociedade em que o ente estatal executa as funções corretivas, juntamente com as outras funções, chamadas de penitenciárias, reproduzidas pelas práticas de aprisionamento ${ }^{19}$.

18 SCHEERER, H.; STEINERT, C.; FOLTER, M. Abolicionismo penal. Buenos Aires: Ediar Sociedad Anónima, 1989. p. 22.

${ }^{19}$ FONSECA, Marcio Alves da. Michel Foucault e o direito. São Paulo: Max Limonad, 2002. 
Nesse panorama, percebe-se que a autodefesa e a autocomposição deixam de ser as únicas formas compositivas de litígios, o que não legitima o poder público a punir sem oferecer o devido processo legal e a ampla defesa ao acusado. É pelo processo que se busca tutelar os direitos à vida, à liberdade, à honra e à integridade das pessoas enquanto agentes sociais. No entanto, parece parodoxal, pois a prisão acaba tornando-se um substituto do gueto e uma instituição "fora da lei". Diante disso, Wacquant ${ }^{20}$ problematiza:

[...] para que serve, finalmente a prisão no século XXI? Seria fácil perceber, se tal questão fosse colocada, que, na verdade na verdade, ninguém sabe mais por que se trancafiam as pessoas. Invoca-se ritualmente a filosofia terapêutica e continua-se a acreditar e fazer acreditar que a prisão tem por missão "reformar" e "reinserir" seus internos enquanto tudo da arquitetura $[\ldots]$.

Em tal dimensão procura-se demonstrar que o projeto da modernidade é caracterizado pelo equilíbrio entre a regulação e a emancipação, o que, por sua vez, com a lógica da cultura punitiva efetivamente se inviabiliza ${ }^{21}$.

De acordo com Bobbio, uma das funções mais frequentemente atribuídas ao direito é a repressão dos comportamentos desviantes, por meio do direito penal. Para ilustrar essa afirmação, o autor se utiliza de uma comparação entre direito e medicina, expondo que, assim como a medicina, o direito não possui uma função voltada à prevenção das doenças sociais, mas desempenha uma função terapêutica, voltada a tratar as doenças - o que não pressupõe a cura - depois de já manifestadas ${ }^{22}$.

Para o processo político, o crime é igualmente um instrumento favorável. A manifestação de um posicionamento em relação à criminalidade é uma maneira importante de se inserir no meio social. Logo, os reais problemas e as necessidades que estão por trás de um crime são desconsiderados pelo sistema atual, que tem como fundamento a culpa legal - altamente técnica - e não a culpa factual - retirada da experiência ${ }^{23}$.

\footnotetext{
${ }^{20}$ WACQUANT, Loic. Punir os pobres: a nova gestão da miséria dos Estados Unidos. Rio de Janeiro: Bastos, 2001. p. 155.

${ }^{21}$ SANTOS, Boaventura De Sousa. Pela mão de Alice: o social e o político na pós-modernidade. $3^{\mathrm{a}}$ ed. São Paulo: Cortez, 1997.

${ }^{22}$ BOBBIO, Norberto. Da estrutura à função: novos estudos de teoria do direito. Barueri: Manole, 2007.

${ }^{23}$ ZEHR, Howard. Trocando as lentes: um novo foco sobre o crime e a justiça - justiça restaurativa. São Paulo: Palas Athena, 2008.
} 
Nesse viés, Zehr ${ }^{24}$ afirma que o principal motivo do fracasso do sistema atual de justiça é a lente pela qual os sujeitos olham o crime, já que se construiu uma visão da realidade que parece ser imutável. Portanto, mister se faz trocar essas lentes violentas e alienadas, transpondo aquilo que se convencionou chamar de habitual, comum e normal, mas que apenas demonstra a insistência humana no erro, no insucesso e na ineficácia de um sistema que raramente pode cumprir com a sua função primordial, ou seja, de reintegração social.

Salienta-se, como contributo na busca pelo rompimento de tais proposições excludentes, eis a Criminologia Crítica, representada pelo paradigma da reação social e da vitimologia que surgem para questionar a postura assumida pelo direito penal, apontando para um processo conciliador entre as partes envolvidas no conflito, pois, à medida que se intensifica os meios de socialização e de construção de consensos, diminui a necessidade das formas tradicionalmente exercidas pelos meios de coação, isto é, do próprio direito ${ }^{25}$.

O redescobrimento da vítima ocorreu, porém, que, com o surgimento da noção de "bem jurídico", surgiu uma objetivação da figura da vítima, deixando ela de ser o sujeito sobre o qual recairia a ação delitiva, que sofreria a conduta delituosa, passando a ser o sujeito portador de um valor, o bem jurídico, exatamente o que, realmente, vem a ser lesado ${ }^{26}$. Nessa seara, Sumariva ${ }^{27}$ considera vítima " $[. .$.$] a pessoa$ que sofre danos de ordem física, mental e econômica, bem como a que perde direitos fundamentais, através de atos ou omissões que consistem em violação a normas penais, incluindo aquelas que prescrevem abuso de poder".

Feita a análise do abolicionismo enquanto uma corrente de pensadores que desconstrói do imaginário social o discurso das prisões como resposta efetiva contra as condutas crimininalizantes, bem como rompe com a falácia de justiça, mister seguir a abordagem de desconstrução do sistema atual de justiça no enfrentamento à violência de gênero contra a mulher, e a necessidade de se pensar novas possibilidades por meio das práticas restaurativas.

\footnotetext{
${ }^{24}$ ZEHR, Howard. Trocando as lentes: um novo foco sobre o crime e a justiça - justiça restaurativa. São Paulo: Palas Athena, 2008.

${ }^{25}$ BOBBIO, Norberto. Da estrutura à função: novos estudos de teoria do direito. Barueri: Manole, 2007.

${ }^{26}$ SANTANA, Selma Pereira de. Justiça Restaurativa: a reparação como consequência jurídico-penal autônoma do delito. Rio de Janeiro: Lumen Juris, 2010.

${ }^{27}$ SUMARIVA, Paulo. Criminologia: teoria e prática. Niterói: Impetus, 2013. p. 51.
} 


\section{ENTRE PRÁTICAS RESTAURATIVAS E RETRIBUTIVAS: A LEI MARIA DA PE- NHA, A TIPIFICAÇÃO DO FEMINICÍDIO E OS AVANÇOS E DESAFIOS DO PO- DER JUDICIÁRIO}

A Justiça Restaurativa tem se tornado uma espécie de busca de sentido das pessoas envolvidas em espaços que justificam a sua existência para a administração de conflitos e para a tentativa de pacificação social, como a família, a comunidade, a escola e o próprio Poder Judiciário, correndo-se o risco da fragilização pela polarização ou o esvaziamento da criticidade por parte do cidadão.

De uma maneira bastante geral, pode-se dizer que a Justiça Restaurativa é vista como uma forma de resolução de conflitos distinta da imposta pelo modelo de justiça penal tradicional. Possui princípios diferentes dos sustentados pelo modelo tradicional (baseado no processo penal e na imposição de penas) e propõe, dentre outras coisas, a participação da vítima e do ofensor (investigado/réu/apenado) na resolução do conflito, a reparação do dano decorrente do delito (simbólica e/ou materialmente) e a responsabilização do ofensor de maneira não estigmatizante e excludente ${ }^{28}$.

Mostra-se preocupante e necessário o enfrentamento dessa postura social e individual com profundas reflexões que não deixam de perpassar pelas seguintes inquietudes: qual o sentido de justiça para as pessoas? Por que a Justiça Restaurativa sendo um conjunto de princípios e práticas em uma comunidade está se tornando uma política judiciária no Brasil podendo sucumbir-se em meio às práticas retributivas, heranças dadas pelo sistema jurídico criminal constituído pela lógica da racionalidade instrumental?

Acredita-se que uma das alternativas possíveis para o fim da violência contra a mulher e para a igualdade de gênero seja a educação tanto de homens como de mulheres $^{29}$. Absorvendo as experiências, edifica-se o papel da operadora jurídica, que acredita no sujeito social, mais no sujeito e suas subjetividades, a grande questão está em pensar na compatibilidade das práticas restaurativas desenvolvidas na área da infância e da juventude para os casos que envolvem violência de gênero.

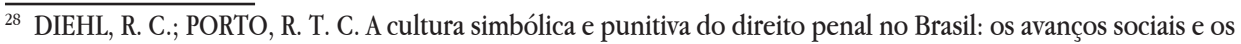
desafios da política nacional de justiça restaurativa a partir da resolução $\mathrm{n}^{\circ} .225 \mathrm{CNJ} / 2016$. Revista Publicatio UEPG: Ciências Sociais Aplicadas, Ponta Grossa, v. 23, n. 3, p. 271-265, set./dez. 2016.

29 TREVISAN, Isabel Pires. Experiência do grupo de acompanhamento de agressores desenvolvido em Bento Gonçalves. In: Rio Grande do Sul. Assembleia Legislativa. Comissão de Cidadania e Direitos Humanos. Relatório Lilás - 2012-2013 Porto Alegre: Assembleia Legislativa: 2013. 
Pode-se adiantar a dizer que a forma trabalhada com os agressores ao gênero é uma prática restaurativa.

Para pensar sobre as subjetividades dos sujeitos, liberdade, direitos e lei, são interessantes as posições de Hobbes, Locke e de Montesquieu. Conforme o primeiro, quando surge a lei é porque morre o poder natural do sujeito, logo, para ele viver com o soberano, abre mão de seus poderes e capacidades, sendo lhe permitido apenas o que a lei concede e não devendo fazer o que a lei proíbe. Para o segundo pensador a subjetividade real do sujeito tão pouco aparece no direito, pois também a sua subjetividade é constituída desde a lei. E para terceiro e último, a liberdade dos seres humanos se fundamenta a partir da segurança do ordenamento jurídico ${ }^{30}$.

A partir dessas lógicas construtivas de pensamento para avançar e desvelar a real subjetividade dos sujeitos, primeiramente é fundamental criticar, desconstruir, refletir sobre o papel do direito nas vidas humanas. Significa dizer, se realmente ele reproduz o controle o possibilita a emancipação. Do mesmo modo, criticar os direitos humanos, que podem estar na mesma lógica de reprodução despótica da legalidade ${ }^{31}$.

$\mathrm{Na}$ mesma linha de raciocínio há de se considerar e reafirmar que a Lei Maria da Penha e a Lei 13.104/2015 não coíbem a violência contra a mulher, pois o homem não demonstra consciência dos seus atos. Além disso, o ciclo de violência se retroalimenta, pois ambos envolvidos (o homem, a mulher e a sua família) são vítimas do contexto. Não se quer com isso banalizar a violência, mas apenas chamar a atenção da sociedade, do poder público, que não basta pensar em condutas criminalizadoras (como criação de leis, é o que se deu com a Maria da Penha e com a lei do feminicídio), é preciso avançar compreendendo o papel do direito socioassistencial dos municípios. Por isso, nesses espaços e não exclusivamente os judicializados ou institucionalizados dá para construir ambientes propícios para trabalhar com a lógica dialógica da prática restaurativa tanto com os agressores quanto das mulheres (ofendidas) e seus familiares.

A violência doméstica é complexa e quando ela torna-se visível muitos laços foram rompidos e destruídos. De qualquer sorte, não se espera com a forma alternativa de enfrentamento ao conflito reaproximar o casal para a convivência matrimonial; o que efetivamente se quer é que ambos percebam que é possível seguir em

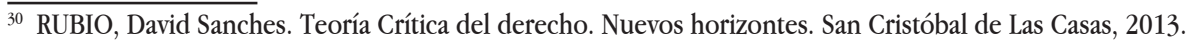

${ }^{31}$ RUBIO, David Sanches. Teoría Crítica del derecho. Nuevos horizontes. San Cristóbal de Las Casas, 2013.
} 
frente, tomar outro rumo e empoderar-se novamente das suas vidas, zelando pelas crianças, que se não acompanhadas ou assistidas acabam reproduzindo papéis, bem como o ciclo da violência para suas vidas.

Nesse aspecto que é possível pensar nas práticas restaurativas: nos círculos restaurativos ou de construção de paz, para que esses homens reconstruam um caminho de resignificação e compreensão, de o quanto manter a convivência com a ex-companheira não é somente violento ou destrutivo para ela, mas para ele e seus filhos.

Nos tempos atuais, cada vez mais tem-se buscado (re)pensar no sentido de justiça dado às relações humanas, que se quer alcançar em face a determinados conflitos sociais inerentes dos mais variados espaços ocupados pelo ser humano. Nesse viés, a Justiça Restaurativa é uma possibilidade de justiça alicerçada na multiplicidade humana e valorativa, onde se propõe a restauração da responsabilidade, da liberdade e da harmonia, por meio do sentimento de pertencimento e senso de comunidade.

Não se resolvem os conflitos com a estrutura antiga, se faz necessário um espaço democrático amplo e de maior proximidade com a comunidade para juntos (Poder Judiciário, o município e os demais atores da rede) elaborarem as melhores estratégias de não conflituosidade. Pode-se afirmar que existe uma preocupação em transformar os espaços decisórios em cenários menos burocráticos, na construção de espaços de diálogo mais democráticos.

A Justiça Restaurativa pode ser entendida como outra maneira de se enxergar que "o sistema institucional de justiça não é senão reflexo de um padrão cultural, historicamente consensual, pautado pela crença na legitimidade do emprego da violência como instrumento compensatório das injustiças e na eficácia pedagógicas das estratégias punitivas"32.

Para alguns a Justiça Restaurativa é um processo de encontro, um método para lidar com o crime e a injustiça que inclui os interessados na decisão sobre o que efetivamente deve ser feito. Para outros, significa uma mudança na concepção de justiça, que se pretende ao ignorar o dano causado pelo delito privilegiar a reparação em detrimento da imposição de uma pena. Outros entendem que se trata de um rol de valores centrados na cooperação e na resolução do conflito, forma de concepção reparativa. "Por fim, ela busca uma transformação nas estruturas da sociedade

\footnotetext{
32 ZEHR, Howard. Justiça Restaurativa. São Paulo: Palas Athena, 2012. p. 10.
} 
e na forma de interação entre os seres humanos e destes com o meio ambiente"33.

Embora a Justiça Restaurativa seja um movimento ainda novo e emergente na sociedade moderna, existe um crescente consenso internacional em relação a seus princípios, inclusive documentos da ONU e da União Europeia, que validam e recomendam as práticas restaurativas para todos os países. Na Resolução n⿳0 2000/12, de 24 de julho de 2000, do Conselho Econômico e Social das Nações Unidas, a ONU divulga os Princípios Básicos para a Utilização de Programas de Justiça Restaurativa em Matéria Criminal.

Diga-se de passagem, nas sociedades ocidentais, a Justiça Restaurativa é implementada utilizando os modelos de tradições indígenas do Canadá, dos Estados Unidos e da Nova Zelândia. A partir de 1989, a Nova Zelândia fez da Justiça Restaurativa o centro de todo o seu sistema penal para a infância e a juventude. Apesar disso, o termo "Justiça Restaurativa" recepcione uma ampla gama de programas e práticas, no seu bojo ela é um conjunto de princípios, uma filosofia, uma série alternativa de perguntas paradigmáticas, que, em última análise, oferece uma estrutura alternativa para se pensar nos danos ${ }^{34}$.

Corrobora-se que a instituição de práticas restaurativas configura-se como um novo olhar na esfera judiciária, nas relações familiares e comunitárias, abrindo um horizonte de participação democrática e de autonomia, ao construir espaços específicos que possibilitam o diálogo pacífico entre as partes envolvidas em um conflito, especialmente no que se refere à violência de gênero. "Não raro, vítimas, ofensores e membros da comunidade sentem que o sistema deixa de atender adequadamente às suas necessidades" 35 .

Inúmeros entendimentos errôneos sobre o real sentido da Justiça Restaurativa deturpam sua aplicação, assim é fundamental definir aquilo que ela não é. A Justiça Restaurativa não tem como objeto principal o perdão ou a reconciliação, esta é uma escolha que fica totalmente a cargo dos envolvidos; a Justiça Restaurativa não é mediação, pois em um conflito mediado se presume que as partes atuem em um mesmo nível ético, geralmente com responsabilidades que deverão ser partilhadas. Ainda que o termo "mediação" tenha sido adotado desde o início dentro do campo das práticas restaurativas, ele vem sendo cada vez mais substituído por termos como

\footnotetext{
33 PALLAMOLLA, Raffaella da Porciuncula. Justiça restaurativa: da teoria à prática. São Paulo: IBCCRIM, 2009. p. 59.

${ }^{34}$ ZEHR, Howard. Justiça Restaurativa. São Paulo: Palas Athena, 2012.

35 ZEHR, Howard. Justiça Restaurativa. São Paulo: Palas Athena, 2012. p. 15.
} 
"encontro" ou "diálogo". Considera-se ainda que a Justiça Restaurativa não tem por objetivo principal reduzir a reincidência ou as ofensas em série, nem é um programa ou projeto específico. "É um convite ao diálogo e à experimentação e não necessariamente uma alternativa ao aprisionamento" ${ }^{36}$.

O conceito da Justiça Restaurativa fala da justiça como valor e não apenas como instituição, e tem o foco nas necessidades determinantes e emergentes do conflito, de forma a aproximar e corresponsabilizar todos os participantes, com um plano de ações que objetiva restaurar laços familiares e sociais, compensar danos e gerar compromissos futuros mais harmônicos e uma sociedade mais segura. Baseia-se em uma ética de inclusão e de responsabilidade social, no conceito de responsabilidade ativa ${ }^{37}$.

É essencial na aprendizagem da democracia participativa fortalecer indivíduos e comunidades para que assumam o papel de pacificarem seus próprios conflitos e assim interromper as cadeias de reprodução da violência. Nesse sentido, a Justiça Restaurativa e suas práticas são compreendidas como moldadas dentro de um arranjo cultural mais amplo, incorporando conceitos, valores e "visões de mundo" e, ao atuarem, ajudam a gerar e a manter essas formas culturais que adotaram.

A Justiça Restaurativa implementada é o resultado de um processo de lutas, alianças e transformações de aspectos culturais anteriores à sua implementação e aqueles por ela veiculados. Com isso, reconhece-se o princípio da não neutralidade, o compromisso com o resgate do tecido social por meio da resolução do conflito e o compromisso em devolver à sociedade essa resolução, pelo (re)empoderamento da fala ${ }^{38}$.

O Poder Judiciário tem se valido de outras formas de administração de conflitos para enfrentar a violência contra a mulher, porém, não têm sido exitosas suas "boas práticas", por diversas razões:

1. A Lei Maria da Penha não é uma lei criminalizadora, ao contrário, deveria ser uma prática restaurativa quando sugere eu seus artigos 12,35 o encaminhamento do agressor ao centro para reeducação. Tem-se diversos artigos despenalizadores, mas de cunho preventivo e educativo que se

\footnotetext{
${ }^{36}$ ZEHR, Howard. Justiça Restaurativa. São Paulo: Palas Athena, 2012. p. 21.

${ }^{37}$ PORTO, R. T. C.; COSTA, M. M. M. Homens autores de violência de gênero e a justiça restaurativa enquanto política de prevenção ao feminicídio. Porto Alegre: Imprensa Livre, 2016.

38 SALM, J.; LEAL, J. S. A Justiça Restaurativa: multidiemensionalidade humana e seu convidado de honra. Revista Sequência, Florianópolis, n. 64, 2012.
} 
tornam ineficazes, pois o sistema de justiça não está preparado e não trabalha com uma rede interdisciplinar. Ao se reconhecer a necessidade da rede e as suas potencialidades, também se reconhece que a questão da violência contra a mulher perpassa o âmbito jurídico e recai sobre a questão psicossocial;

2. É preciso realmente utilizar o direito penal para responsabilizar e intervir. No entanto, o que ocorre é a revitimização e a seletividade do sistema penal retributivo criado para se retroalimentar de pessoas coisificadas e descartáveis pela sociedade de risco;

3. A utilização da Justiça Restaurativa em todas as dimensões e inclusive nas questões de violência contra mulher envoltas por práticas retributivas de um Judiciário político e de cultura europeia pode causar o seu esvaziamento, tornando-se coprodutora do direito penal. Portanto, inviabilizando-se enquanto política pública de prevenção e enfrentamento à violência contra a mulher.

A violência contra a mulher é um crime aos direitos humanos e representa uma grave adversidade na sociedade. A análise dos feminicídios e das circunstâncias como ocorreram é de especial importância no combate à violência doméstica e o aprimoramento da ação policial na prevenção e investigação de tais crimes. Ademais contribui para efetiva transversalidade e integração da atuação da polícia com todo sistema de justiça.

A Lei 13.104/2015, legislação brasileira do feminicídio, classifica-o como crime hediondo e com agravantes quando acontece em situações específicas de vulnerabilidade (gravidez, menor de idade, na presença de filhos, etc.). As definições dessa lei, embora controversas e alvo de merecidas críticas por parte de diversos operadores da lei e dos movimentos sociais, principalmente os de mulheres, deverão ser nosso ponto de partida para a caracterização de letalidade intencional violenta por condição de gênero, que se irá utilizar ao longo do estudo.

Entende a lei que existe feminicídio quando a agressão envolve violência doméstica e familiar, ou quando evidencia menosprezo ou discriminação à condição de mulher, caracterizando crime por razões de condição do gênero feminino. Devido às limitações dos dados atualmente disponíveis, entende-se por feminicídio as agressões cometidas contra uma pessoa do gênero feminino no âmbito familiar da vítima que, de forma intencional, causam lesões ou agravos à saúde que levam à 
sua morte.

É importante refletir sobre a dimensão do fenômeno sociojurídico e político conhecido por feminicídio, que em alguns países da América Latina, inclusive no Brasil, é considerado crime. Apesar desse recepcionamento jurídico, a sua efetividade nos países que adotaram deixam dúvidas e desafios a serem enfrentados. A cultura jurídica de criação de lei ou a prática discursiva da "sobrelei" (cria-se uma lei, em cima de uma mesma lei), não é um impeditivo para que o Brasil saia da $5^{\text {a }}$ posição do ranking em feminicídio no contexto de 84 países.

Para tornar mais visível essa questão em âmbito latino-americano, traz-se abaixo uma tabela com os países americanos que incluíram o feminicídio em suas legislações de acordo com dados do site Compromisso e Atitude:

Tabela 1. A tipificação do feminicídio na América Latina

(Continua)

\begin{tabular}{|c|c|c|c|}
\hline PAÍS & LEGISLAÇÃO & EM VIGOR DESDE & PENA \\
\hline Argentina & $\begin{array}{l}\text { Reforma do Código Penal (mo- } \\
\text { dificação do artigo 80) }\end{array}$ & $\begin{array}{l}\text { Promulgada em } 11 \text { de } \\
\text { dezembro de } 2012\end{array}$ & $\begin{array}{l}\text { Reclusão ou prisão } \\
\text { perpétua }\end{array}$ \\
\hline Bolívia & $\begin{array}{l}\text { Lei Integral para garantir às Mu- } \\
\text { lheres uma vida livre de violên- } \\
\text { cia. Incorpora no Código Penal } \\
\text { o delito do feminicídio. Reforma } \\
\text { do Código Penal (artigo 83) }\end{array}$ & Março de 2013 & $\begin{array}{l}30 \text { anos de prisão sem } \\
\text { direito a recorrer }\end{array}$ \\
\hline Brasil & $\begin{array}{l}\text { Lei Nacional que altera o Código } \\
\text { Penal Brasileiro com a inclusão } \\
\text { do feminicídio como qualifi- } \\
\text { cadora de homicídio e crime } \\
\text { hediondo }\end{array}$ & $\begin{array}{l}\text { Lei } n^{\circ} 13.104 \text {, de } 09 \\
\text { de março de } 2015\end{array}$ & $\begin{array}{l}\text { Estabelece agravante } \\
\text { para o crime de } \\
\text { homicídio qualificado }\end{array}$ \\
\hline Chile & $\begin{array}{l}\text { Reforma do Código Penal (artigo } \\
390 \text { ) }\end{array}$ & $\begin{array}{l}\text { Lei } n^{\circ} 20.480 \text {, de } 14 \\
\text { de dezembro de } 2010 \text {, } \\
\text { publicada em } 18 \mathrm{de} \\
\text { dezembro de } 2010 \text {, } \\
\text { vigente no dia de sua } \\
\text { publicação }\end{array}$ & $\begin{array}{l}\text { Pena máxima (prisão } \\
\text { perpétua qualificada, } \\
\text { ou seja, } 40 \text { anos de } \\
\text { prisão efetiva antes da } \\
\text { tentativa de redução } \\
\text { da pena) }\end{array}$ \\
\hline Colômbia & $\begin{array}{l}\text { Reforma do Código e do Pro- } \\
\text { cedimento Penal, Lei n } 1257 \\
\text { (modifica o artigo } 104 \text { do Códi- } \\
\text { go Penal e inclui o feminícidio } \\
\text { como agravante) }\end{array}$ & $\begin{array}{l}\text { Promulgada em } 04 \text { de } \\
\text { dezembro de } 2008\end{array}$ & $\begin{array}{l}\text { De } 33 \text { a } 50 \text { anos de } \\
\text { prisão }\end{array}$ \\
\hline
\end{tabular}


(Continua)

\begin{tabular}{|c|c|c|c|}
\hline PAÍS & LEGISLAÇÃO & EM VIGOR DESDE & PENA \\
\hline Costa Rica & $\begin{array}{l}\text { Lei de Penalização da Violência } \\
\text { contra as mulheres }\end{array}$ & $\begin{array}{l}\text { Lei } n^{\circ} 8.589 \text {, de } 25 \text { de } \\
\text { abril de } 2007 \text {, publi- } \\
\text { cada e vigente a partir } \\
\text { de } 30 \text { de maio de } 2007\end{array}$ & $\begin{array}{l}\text { Prisão de } 20 \text { a } 35 \\
\text { anos, e desqualifica- } \\
\text { ção de } 1 \text { a } 12 \text { anos }\end{array}$ \\
\hline El Salvador & $\begin{array}{l}\text { Lei especial integral para uma } \\
\text { vida livre de violência para as } \\
\text { mulheres }\end{array}$ & $\begin{array}{l}\text { Lei } \mathrm{n}^{\mathrm{O}} 520 \text {, de } 25 \text { de } \\
\text { novembro de } 2010, \\
\text { vigente a partir de } 1^{\mathrm{o}} \\
\text { de janeiro de } 2012\end{array}$ & $\begin{array}{l}\text { Prisão de } 20 \text { a } 35 \text { anos } \\
\text { Figura agravada: pri- } \\
\text { são de } 30 \text { a } 50 \text { anos }\end{array}$ \\
\hline Equador & $\begin{array}{l}\text { Reforma do Código Orgânico } \\
\text { Integral Penal (Artigo 141) }\end{array}$ & $\begin{array}{l}\text { Entrou em vigor a par- } \\
\text { tir do dia } 10 \text { de agosto } \\
\text { de } 2014\end{array}$ & Prisão de 22 a 26 anos \\
\hline Guatemala & $\begin{array}{l}\text { Lei contra o feminicídio e outras } \\
\text { formas de violência contra a } \\
\text { mulher }\end{array}$ & $\begin{array}{l}\text { Decreto 22-2008, de } \\
02 \text { de maio de } 2008, \\
\text { publicado em } 07 \text { de } \\
\text { maio de } 2008 \text {, vigente } \\
\text { sete dias após a publi- } \\
\text { cação (15 de maio de } \\
2008)\end{array}$ & Prisão de 25 a 50 anos \\
\hline Honduras & Reforma do Código Penal & $\begin{array}{l}\text { Aprovada em fevereiro } \\
\text { de } 2013\end{array}$ & $\begin{array}{l}\text { De } 30 \text { a } 40 \text { anos de } \\
\text { prisão }\end{array}$ \\
\hline México & $\begin{array}{l}\text { Reforma do Código Penal Fede- } \\
\text { ral (artigo 325) }\end{array}$ & $\begin{array}{l}\text { Reforma em } 13 \text { de ju- } \\
\text { nho de } 2012 \text {, vigente a } \\
\text { partir de } 15 \text { de junho } \\
\text { de } 2012\end{array}$ & $\begin{array}{l}\text { Prisão de } 40 \text { a } 60 \\
\text { anos, e de } 500 \text { a } 1.000 \\
\text { dias-multa. Perda de } \\
\text { direitos em relação à } \\
\text { vítima, inclusos os de } \\
\text { caráter } \\
\text { sucessório }\end{array}$ \\
\hline Nicarágua & $\begin{array}{l}\text { Lei integral contra a violência } \\
\text { feita às mulheres }\end{array}$ & $\begin{array}{l}\text { Lei } \mathrm{n}^{\circ} 779 \text {, de } 20 \text { de } \\
\text { fevereiro de } 2012 \text {, } \\
\text { publicada em } 22 \mathrm{de} \\
\text { fevereiro de } 2012, \\
\text { vigente } 120 \text { dias após } \\
\text { a publicação (junho } \\
\text { de 2012) }\end{array}$ & $\begin{array}{l}\text { Prisão de } 15 \text { a } 20 \text { anos } \\
\text { quando ocorrer em } \\
\text { âmbito público. } \\
\text { Prisão de } 20 \text { a } 25 \text { anos } \\
\text { quando ocorrer em } \\
\text { âmbito privado. } \\
\text { Analisadas as circuns- } \\
\text { tâncias, pode chegar } \\
\text { ao máximo de } 30 \text { anos } \\
\text { de prisão }\end{array}$ \\
\hline Panamá & $\begin{array}{l}\text { Lei } 82 \text { tipifica o feminicídio e a } \\
\text { violência contra as mulheres }\end{array}$ & $\begin{array}{l}\text { Lei } 82 \text { de } 24 \text { de outu- } \\
\text { bro de } 2013\end{array}$ & Prisão de 25 a 30 anos \\
\hline
\end{tabular}


Conclusão

\begin{tabular}{|c|c|c|c|}
\hline PAÍS & LEGISLAÇÃO & EM VIGOR DESDE & PENA \\
\hline Peru & $\begin{array}{l}\text { Reforma do Código Penal (artigo } \\
107 \text { ) }\end{array}$ & $\begin{array}{l}\text { Lei } n^{\circ} 29.819 \text {, publi- } \\
\text { cada em } 27 \text { de dezem- } \\
\text { bro de } 2011\end{array}$ & $\begin{array}{l}\text { Pena privativa de } \\
\text { liberdade não inferior } \\
\text { a } 15 \text { anos. Pena priva- } \\
\text { tiva de liberdade não } \\
\text { inferior a } 25 \text { anos se } \\
\text { constarem agravantes } \\
\text { dos incisos } 1 \text { a } 4 \text { do } \\
\text { artigo } 108 \text { do Código } \\
\text { Penal }\end{array}$ \\
\hline $\begin{array}{l}\text { República } \\
\text { Dominicana }\end{array}$ & $\begin{array}{l}\text { Reforma do Código Penal (artigo } \\
100 \text { ) }\end{array}$ & $\begin{array}{l}\text { Lei } \mathrm{n}^{\circ} 550 \text { publicada } \\
\text { em } 19 \text { de dezembro } \\
\text { de } 2014 \text { reforma o } \\
\text { Código Penal da Repú- } \\
\text { blica Dominicana }\end{array}$ & Prisão de 30 a 40 anos \\
\hline Venezuela & $\begin{array}{l}\text { Reforma da Lei Orgânica pelo } \\
\text { Direito das Mulheres a uma vida } \\
\text { livre de violência (artigo 57) }\end{array}$ & $\begin{array}{l}\text { Lei de Reforma pro- } \\
\text { mulgada no dia } 25 \text { de } \\
\text { novembro de } 2014\end{array}$ & Prisão de 15 a 30 anos \\
\hline
\end{tabular}

Fonte: Compromisso e Atitude ${ }^{39}$.

Resumidamente, a forma mais extrema da violação em direitos humanos contra as mulheres é conhecida como sendo o feminicídio; é um fenômeno que perdura ao longo dos tempos. É interessante destacar que enquanto o homem sofre com a violência ocorrida no espaço público que, geralmente cometida por outro homem, a mulher sofre mais com a violência ocorrida no âmbito doméstico e os seus agressores são os companheiros ou ex-companheiros.

Não se quer deixar de reconhecer com isso a importância de enfrentar o fenômeno multifacetal da violência, que reside em um dos seus axiomas, no fato de os homens não compreenderem ou assim desejarem manter-se, quando as mulheres querem ocupar o espaço público, decidir sobre a reprodução da prole e sobre a libido. Ou seja, a partir do instante em que as mulheres começam a perceber e reconhecer que são sujeitos sociais, com direito à condição humana, não mais de escravas ou submissas de uma cultura patriarcal, que as reduziu à função materna e doméstica, pelo motivo de existir, alguns homens não aceitam e consequentemente querem manter seu poder não só simbolicamente, mas pela materialização da violência.

39 COMPROMISSO E ATITUDE. Legislações da América Latina que penaliza o feminicídio. Disponível em: $<$ http://www.compromissoeatitude.org.br/legislacoes-da-america-latina-que-penalizam-o-feminicidio/> . Acesso em: 02 fev. 2018. 


\section{CONSIDERAÇÕES FINAIS}

Houve a preocupação em trabalhar com os principais abolicionistas penais dentro da criminologia crítica, também mencionando as contribuições de Michel Foucault, com a premissa de desconstrução da efetividade do sistema prisional, relacionando a Lei Maria da Penha, que apresenta uma lógica punitiva quando se busca a referida lei para exclusivamente punir ou prender os homens autores de violência de gênero. Quando algumas mulheres enfatizam nos seus discursos o discurso da punição sem outras possibilidades de atendimento aos seus agressores, acaba se igualando em comportamento com ele, o que também é reflexo da cultura patriarcal.

Não se quer dizer com isso que os homens autores de violência de gênero não devam ser responsabilizados pelos seus atos, pois conforme dados recentes da violência contra a mulher são preocupantes e merecem serem tratados com seriedade pelo poder público e a sociedade. Aliás, a Lei n. 11.340/2006 e a Lei n. 13.140/2015 tiveram um papel preponderante enquanto política pública, pois começaram a dar mais visibilidade a esta violência de ordem estrutural, simbólica e violadora dos direitos humanos dos envolvidos.

Buscar pela via da lei ou restringir o direito a lei com o fito de enfrentamento e inibição de atos de barbárie dos homens contra as mulheres não rompe com o ciclo da violência e nem garante às mulheres o empoderamento e a liberdade de exercer sua cidadania dentro do espaço público, bem como do doméstico, sendo que nesse ela na sua maioria exerce a função de chefe e zelo pela prole. É preciso ter cuidado com a lógica da lei que pode virar uma perpetuação da lógica punitiva ou não declarada. Não se quer com isso afastar a responsabilização dos comportamentos que afrontam a dignidade do outro, mas quer atentar os pensadores para repensar os aspectos culturais além do direito delimitado pela lei e sim ir ao encontro da transdisciplinaridade pelo pensamento da complexidade.

Não basta aplicar a lei na busca pela punição, a envergadura precisa ir além, se trabalhando com a prevenção e idealizando uma concepção valorativa e filosófica de justiça que auxilie as pessoas a caminharem rumo à erradicação da violência, tendo por pressuposto a educação dos sujeitos para lidar com a diversidade.

Portanto, a Justiça Restaurativa pode ser uma boa prática diversa de política contributiva à segurança pública, na perspectiva de enfrentar e prevenir a violência contra a mulher, se mantida íntegra e não convergida a cultura punitiva do atual sistema criminal retributivo. 


\section{REFERÊNCIAS}

ACHUTTI, Daniel Silva. Justiça restaurativa e abolicionismo penal. São Paulo: Saraiva, 2014.

BOBBIO, Norberto. Da estrutura à função: novos estudos de teoria do direito. Barueri: Manole, 2007.

CHRISTIE, Nils. A indústria do controle do crime: a caminho dos GULAGS em estilo ocidental. Rio de Janeiro: Forense, 1998.

COMPROMISSO E ATITUDE. Legislações da América Latina que penalizam o feminicídio. Disponível em: < http://www.compromissoeatitude.org.br/legislacoes-da-america-latina-que-penalizam-o-feminicidio/> . Acesso em: 02 fev. 2018.

DIEHL, Rodrigo Cristiano; PORTO, Rosane Teresinha Carvalho. A cultura simbólica e punitiva do direito penal no Brasil: os avanços sociais e os desafios da política nacional de justiça restaurativa a partir da resolução $\mathrm{n}^{\circ} .225 \mathrm{CNJ} / 2016$. Revista Publicatio UEPG, Ciências Sociais Aplicadas, Ponta Grossa, v. 23, n. 3, p. 271-265, set./dez. 2016.

ELBERT, Carlos Alberto. Novo manual de criminologia. Porto Alegre: Livraria do Advogado, 2009.

FONSECA, Marcio Alves da. Michel Foucault e o direito. São Paulo: Max Limonad, 2002.

FOUCAULT, Michel. A ordem do discurso. 3. ed. São Paulo: Loyola, 1996.

HULSMAN, Louk; CELIS, Jacqueline Bernat de. Penas perdidas: o sistema penal em questão. Rio de Janeiro: Luam, 1993.

PALLAMOLLA, Raffaella da P. Justiça restaurativa: da teoria à prática. São Paulo: IBCCRIM, 2009.

PORTO, Rosane T. Carvalho; COSTA, Marli M. Moraes da; DIEHL, Rodrigo Cristiano. Justiça Restaurativa e Sinase: Inovações trazidas pela Lei 12.594/12 enquanto política pública socioeducativa a adolescentes autores de atos infracionais. Curitiba: Multideia, 2015.

PORTO, Rosane T. Carvalho; COSTA, Marli M. Moraes da. Homens autores de vio- 
lência de gênero e a justiça restaurativa enquanto política de prevenção ao feminicídio. Porto Alegre: Imprensa Livre, 2016.

RUBIO, David Sanchez. Teoría Crítica del derecho. Nuevos horizontes. San Cristóbal de Las Casas, 2013.

SALM, João; LEAL, Jackson da Silva. A Justiça Restaurativa: multidiemensionalidade humana e seu convidado de honra. Revista Sequência, Florianópolis, n. 64, 2012.

SANTANA, Selma Pereira de. Justiça Restaurativa: a reparação como consequência jurídico-penal autônoma do delito. Rio de Janeiro: Lumen Juris, 2010.

SANTOS, Boaventura de Souza. Pela mão de Alice: o social e o político na pósmodernidade. 3. ed. São Paulo: Cortez, 1997.

SCHEERER, Hulsman; STEINERT, Christie; FOLTER, Mathiense. Abolicionismo penal. Buenos Aires: Ediar Sociedad Anónima, 1989.

SUMARIVA, Paulo. Criminologia: teoria e prática. Niterói: Impetus, 2013.

TREVISAN, I. P. Experiência do grupo de acompanhamento de agressores desenvolvido em Bento Gonçalves. Rio Grande do Sul: Assembleia Legislativa. Comissão de Cidadania e Direitos Humanos. Relatório Lilás - 2012-2013 Porto Alegre: Assembleia Legislativa, 2013.

WACQUANT, Loïc. Punir os pobres: a nova gestão da miséria dos Estados Unidos. Rio de Janeiro: Bastos, 2001.

ZEHR, Howard. Justiça Restaurativa. São Paulo: Palas Athena, 2012.

ZEHR, Howard. Trocando as lentes: um novo foco sobre o crime e a justiça - justiça restaurativa. São Paulo: Palas Athena, 2008. 